\title{
A Survey of LTR Program Industry Partner Satisfaction at Oak Ridge National Lab
}

\author{
By Dr. Terry L. Payne, ORNL LTR Program Manager \\ Dr. Chris Kniel, LBNL LTR Program Manager
}

\begin{abstract}
As a U.S. Department of Energy (DOE) Office of Science (SC) National Laboratory, the Oak Ridge National Lab (ORNL) participates in the Laboratory Technology Research (LTR) Program. The mission of the LTR Program is to advance science and technology, in support of DOE missions, toward innovative applications through cost-shared partnerships with the private sector. The benefits to industry participants include gaining access to world-class researchers and facilities, while the benefits to the ORNL researchers includes leveraging the declining government-provided funds. Thus, the importance placed upon industry partner satisfaction is large, especially if the LTR Program is to be sustained during episodes of government budget constraints. Realizing the critical nature of partner satisfaction, in 1998 the DOE-SC National Laboratories surveyed industrial partners to assess their satisfaction with the cooperative research projects in which they were involved. This paper will describe the survey methodology including development of the questionnaire and a summary of the responses (particularly those which are germane to the ORNL.) The results of the survey will be categorized as follows: (1) Desire to partner again with ORNL; (2) Benefits obtained by the company from the partnership; and (3) LTR Program ratings assigned in 11 key areas (i.e., quality of work, expertise, protection of intellectual property, value, facilities, understanding company needs, reliability of funding, schedule responsiveness, project management, contract negotiation, and contract administration.) More information about the LTR Program can be found at http://www.er.doe.gov/production/octr/aeptr/aeptr pr.html.)
\end{abstract}

The Oak Ridge National Laboratory is a U.S. Department of Energy facility operated by the Lockheed Martin Energy Research Corporation under contract DE-AC05-96OR22464.

Key words: research, partnership, government 


\section{INTRODUCTION}

During the 1990s, the U.S. Department of Energy, along with other agencies, began to participate in partnership programs for research and development with the private sector. In late 1997 and early 1998, the Office of Science (formerly Office of Energy Research) multiprogram national laboratories (SC Labs) surveyed industry partners of cost-shared collaborative industrygovernment research projects to identify strengths and weaknesses of the Laboratory Technology Research (LTR) Program from the private sector perspective. The LTR Program supports medium- to high-risk, cost-shared collaborative research projects whose solutions offer U.S. economic benefits, have promising commercial potential, and support DOE missions. In the LTR Program, no Federal funds are provided to industry partners. Each research project has its own specific scope, work plan, budget, schedule, and contract which reflects a formal collaboration between the lab and the company. Companies that participate in the program contribute resources (in-kind resources and funds to the Labs) that are at least equal to and frequently exceed those provided by the DOE. The projects explore the applications of fundamental research to DOE's mission over a full range of scientific disciplines. This report summarizes responses to that partner survey as well as recommendations germane to ORNL.

Questionnaires were sent to several previous and existing industry partners; 18 companies that had previously partnered with ORNL responded. The companies surveyed represented a diverse industry-sector distribution and included companies from biotechnology, computers, advanced materials, and other sectors. By revenue, the companies ranged from less than $\$ 1$ million to more than $\$ 10$ billion annual sales.

When the ORNL responses were grouped with those of the other SC Labs, key findings include:

- $97 \%$ of the survey respondents would like to partner again with one of the labs on a future research project.

- $91 \%$ indicated they had benefited from partnering with the laboratories in the LTR program.

- Written responses indicate that the greatest single benefit to the industry partners is obtaining specialized expertise and capabilities from the labs that are otherwise unavailable.

- The most frequently mentioned program benefits are:

-- Better understanding of the technology.

-- Understanding technology's potential.

-- Leveraging research funds.

-- Tapping expertise otherwise available.

- Responses indicate an industry demand for LTR partnerships that exceeds the DOE funding presently available.

- Areas where the survey results suggest the partnership could be improved include reliability of funding, administrative simplifications, and timeliness in meeting project schedules. 
The survey resulted in three broad recommendations: improvements to funding commitments for multi-year projects; CRADA contractual simplifications; and schedule responsiveness and other operational improvements.

\section{QUESTIONNAIRE DEVELOPMENT AND APPROACH}

The SC Labs, along with the DOE LTR office, developed a 10-point questionnaire concerning the LTR Program to submit to current and past industry partners, which addressed the following points:

- Who has primary responsibility to partner?

- Have you [the industry partner] benefited? If so, how?

- Do you support Lab-Industry collaborations?

- How many potential [Lab-Industry] collaborations do you foresee over the next five years [for your company]?

- Rate the SC Lab [you are working with] both from an importance and a performance perspective in eleven key areas; e.g., technical expertise, schedule responsiveness, reliability of funding, contractual negotiation, quality of work, intellectual property protection, value of work.

- Comment on performance shortfalls and provide suggestions.

- Identify the greatest single benefit of working with the ER Lab

Berkeley Lab coordinated efforts to develop the survey questionnaire and maintain a database of company feedback. Mailing the questionnaires and following up on company responses were handled by each of the SC Labs.

\section{RESPONSIBILITY TO PARTNER}

Of the 18 companies responding to the ORNL survey, almost $89 \%$ indicated that the R\&D Manager or the CEO had the primary responsibility to commit the company to contract with an SC Lab. (Note that some companies said more than 1 person had the responsibility to commit the company.) The following chart summarizes company responses. In most cases, the category "Other" represented the industry principal investigator or the project manager. 


\section{Number of Company Responses}

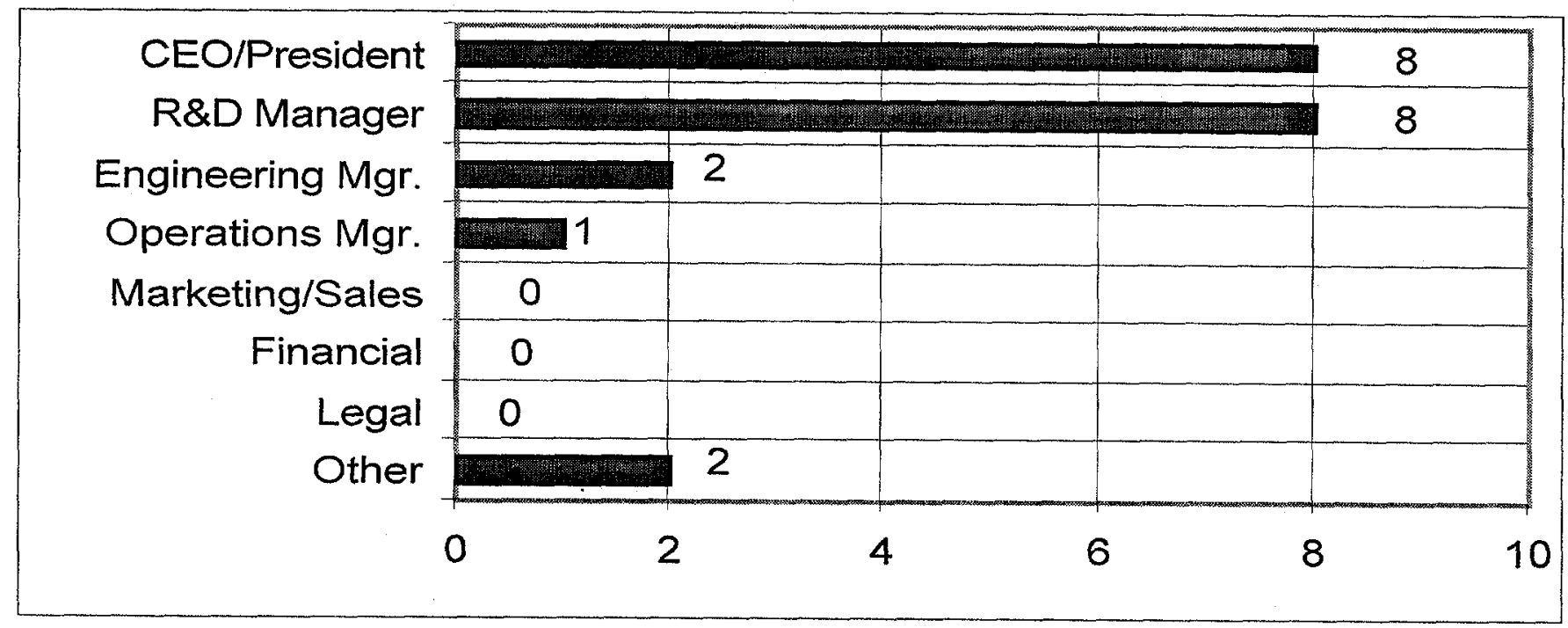

Chart 1 - Who has responsibility to partner?

\section{NUMBER OF COMPANIES BENEFITTING FROM PARTNSERSHIPS WITH ORNL}

The responses overwhelmingly indicate that industry strongly supports the partnership approach and has benefited from the program. Of 18 company responses, the following graph illustrates that 16 companies or $91 \%$ said their company had benefited from an SC Lab collaboration.

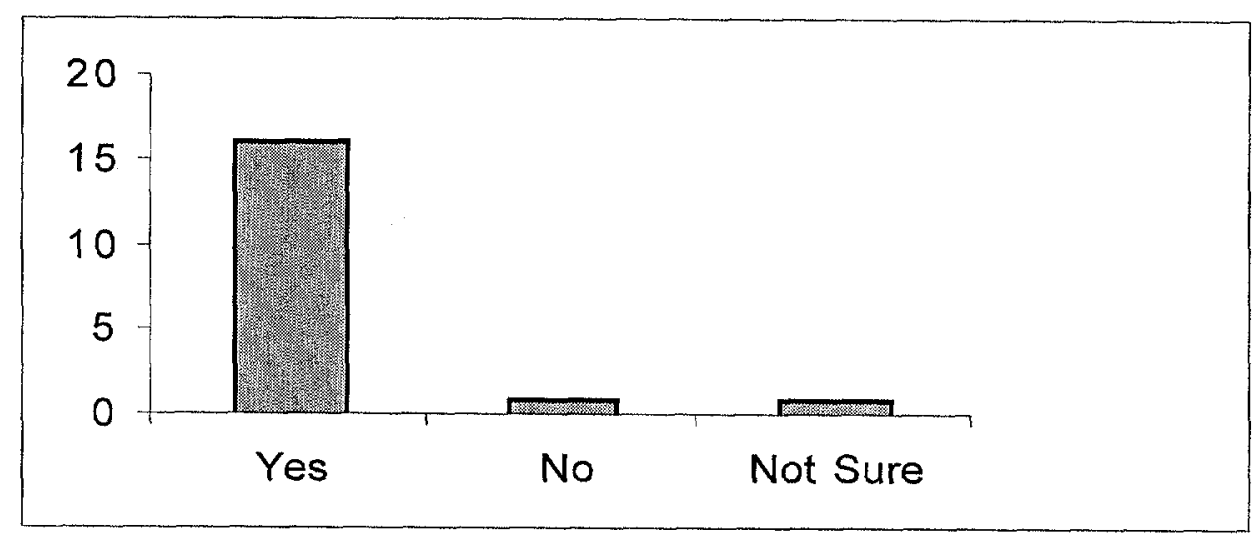

Chart 2 - Companies that have benefited from an ER Lab partnership. 


\section{DEMAND FOR FUTURE RESEARCH COLLABORATIONS}

(This section includes data representing all participating SC Labs.)

Company responses indicate an industry demand for LTR partnerships that exceeds the DOE funding presently available. When asked about future research collaborations, 97\% of the companies said they wanted to collaborate on a future partnership project with one of the labs. Approximately 50\% indicated three or four projects; $7 \%$ indicated between five and nine; and $5 \%$ of the companies wanted to partner on 10 or more projects over the next five years. Only $3 \%$ indicated they did not wish to partner with a lab over the next five years. The following graph (Chart 3) shows partnership demand (from just the 126 companies responding to the survey) over the next five years.

Responses indicate an industry demand for LTR partnerships that exceeds the DOE funding presently available.

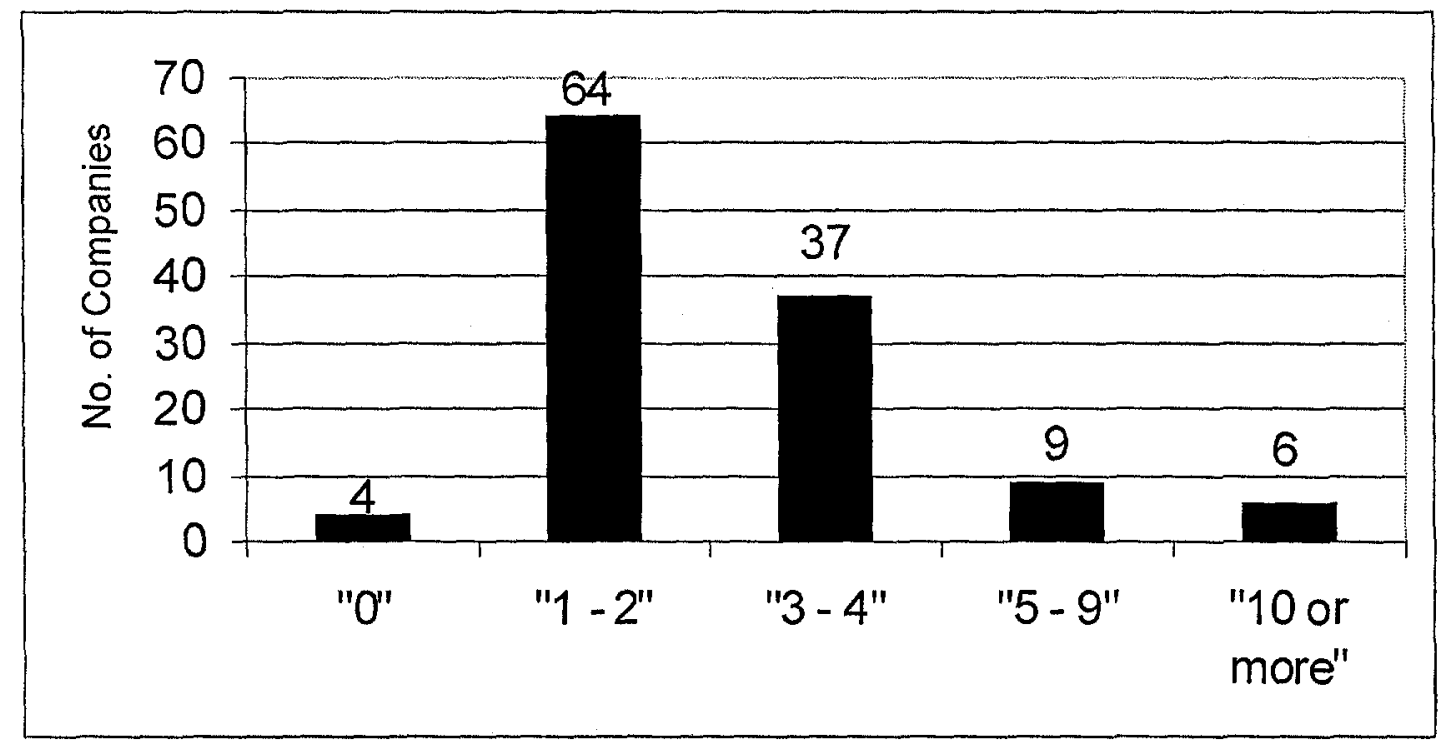

Chart 3 - Industry demand for future collaborations over the next five years.

\section{COMPANIES RATE SC LABS PERFORMANCE}

(This section includes data representing all participating SC Labs.) 
The survey asked companies to evaluate SC Lab's performance in 11 key areas: quality of work, expertise, intellectual property protection, value, facilities, understanding needs, reliability of funding, schedule responsiveness, project management, contract negotiation, and contract administration. Companies were also asked to rank each category in terms of importance, and to comment on differences between performance and importance ratings. All rankings were on a scale of 1 to 5 where 1 is poor, 3 is fair, and 5 is excellent; or for importance, 1 is not important, 3 is somewhat important, and 5 is very important.

Chart 5 indicates how the SC Labs fared in company ratings. From an importance prospective, quality of work, expertise, intellectual property protection, value, facilities, understanding needs, reliability of funding, and schedule responsiveness all ranked above 4 on a scale of 5 .

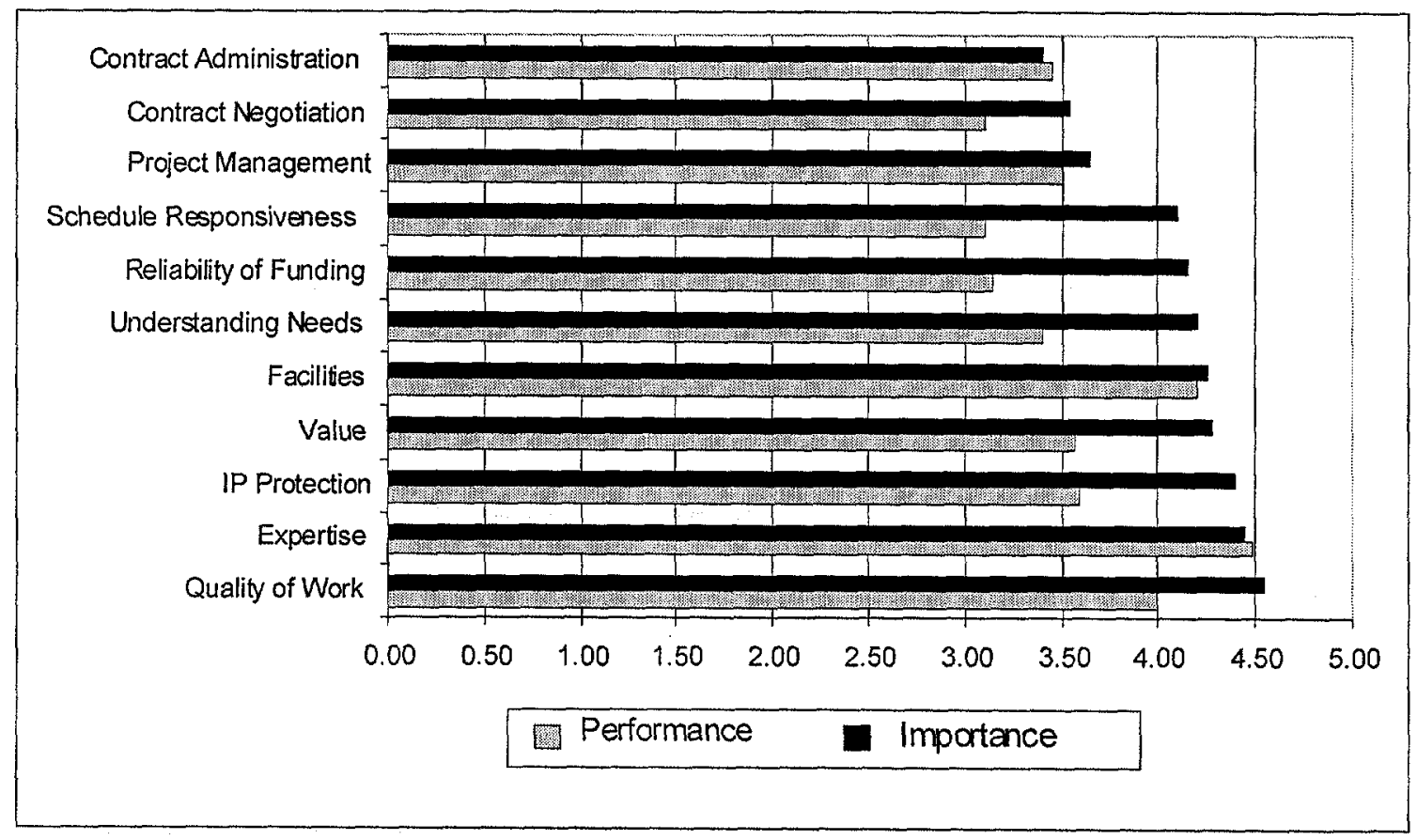

Chart 4 - Performance vs. Importance (rank by importance)

Importance/performance gap could be a measure of potential improvements in the SC Lab's ability to understand and better meet the industry partner's needs. The categories with the greatest gap between importance and performance were:

- Reliability of funding (gap $=1.0$ )

- Schedule responsiveness (gap $=0.99$ )

- Intellectual property protection (gap 0.77 )

- Understanding needs (gap 0.75)

- Value (gap 0.66)

The three areas with the worst performance (corresponding to generally a "fair" ranking) are reliability of funding (3.10), contract negotiation (3.09) and schedule responsiveness (3.07). 


\section{SUGGESTIONS FOR IMPROVEMENT}

Despite the overwhelming support for partnerships expressed by the companies, there was no dearth of suggestions for improvement. Companies offered a number of suggestions for areas needing improvement. Generally, company feedback was provided by the R\&D Manager and/or the company principal investigator directly involved in the collaborative research project. (As with any questionnaire, the responses may or may not represent a formal company perspective.) Suggestions included comments related to funding, simplification of the CRADA process, standardization of intellectual property issues, schedule accountability, understanding company needs and other project management issues.

\section{SUMMARY-WHAT WE HAVE LEARNED}

There are many messages in the company responses, along with many good suggestions. The response rate alone, greater than $40 \%$, is a positive indicator of industry's interest and support of the partnership concept and the program. The survey clearly identified what is important from industry's prospective. Perhaps the key points that emerge are:

- Companies overwhelmingly like Lab collaborations; they have benefited in many ways. Of 126 companies responding to the survey, 115 said they have benefited, and $97 \%$ said they would like to partner again with a national lab. A high degree of overall partner satisfaction is evident.

- Companies partner with the Labs to tap into scientific and technical expertise that otherwise would not be available to them, to use specialized equipment, to leverage resources, and to expand their knowledge base.

- Company responses indicate an industry demand for LTR partnerships that exceeds the DOE funding presently available.

- The Labs (and DOE) received several marks that were only average. Performance can be improved in several areas, including continuity of funding, meeting schedules and contractual simplification.

- There are many other thoughtful company suggestions that can improve the partnership program. Some of these are listed in the Recommendations section that follows.

The survey did not attempt to document DOE or Laboratory benefits from working with industry, nor did it attempt to understand the perspective of companies that have not collaborated in an LTR partnership project.

Authors' Bios: Dr. Terry Payne is the ORNL LTR Program Manager. Dr. Payne received his Ph.D. in strategic management of technology in 1992.

Dr. Chris Kniel is the Lawrence Berkeley National Laboratory LTR Program Manager. 